\title{
Case-control study of paternal occupation and childhood leukaemia in Great Britain, 1962-2006
}

\author{
TJ Keegan*, , KJ Bunch², TJ Vincent ${ }^{2}$, JC King², KA O'Neill², GM Kendall², A MacCarthy'2, NT Fear ${ }^{3}$ \\ and MFG Murphy ${ }^{2}$
}

'Faculty of Health and Medicine, Lancaster University, Faraday Building, Lancaster, LAI 4YD, UK; ${ }^{2}$ Childhood Cancer Research Group, University of Oxford, Oxford, OX3 7LG, UK; ${ }^{3}$ Academic Centre for Defence Mental Health, King's College London, London, SE5 9RJ, UK

BACKGROUND: Paternal occupational exposures have been proposed as a risk factor for childhood leukaemia. This study investigates possible associations between paternal occupational exposure and childhood leukaemia in Great Britain.

METHODS: The National Registry of Childhood Tumours provided all cases of childhood leukaemia born and diagnosed in Great Britain between 1962 and 2006. Controls were matched on sex, period of birth and birth registration subdistrict. Fathers' occupations were assigned to I or more of 33 exposure groups. Social class was derived from father's occupation at the time of the child's birth.

RESULTS: A total of 16764 cases of childhood leukaemia were ascertained. One exposure group, paternal social contact, was associated with total childhood leukaemia (odds ratio I.14, I.05-1.23); this association remained significant when adjusted for social class. The subtypes lymphoid leukaemia (LL) and acute myeloid leukaemia showed increased risk with paternal exposure to social contact before adjustment for social class. Risk of other leukaemias was significantly increased by exposure to electromagnetic fields, persisting after adjustment for social class. For total leukaemia, the risks for exposure to lead and exhaust fumes were significantly $<1$. Occupationally derived social class was associated with risk of LL, with the risk being increased in the higher social classes.

CONCLUSION: Our results showed some support for a positive association between childhood leukaemia risk and paternal occupation involving social contact. Additionally, LL risk increased with higher paternal occupational social class.

British Journal of Cancer (2012) I 07, I652-1659. doi:I0.I038/bjc.20 I2.359 www.bjcancer.com

Published online II September 2012

(c) 2012 Cancer Research UK

Keywords: childhood cancer; childhood leukaemia; epidemiology; paternal occupation; social class

Leukaemia is the most common cancer among children. It accounts for around $30 \%$ of all new cases of cancer in children aged less than 15 years (Parkin et al, 1998). About 500 children in Great Britain develop leukaemia each year, with a peak in incidence at around age 4 years (Swerdlow et al, 2001). The most common leukaemia subtypes in childhood are lymphoid leukaemia (LL), accounting for around $80 \%$ of leukaemia cases, and acute myeloid leukaemia (AML), accounting for about 14\% of cases (Stiller, 2007), as defined in the International Classification of Childhood Cancer version 3 (ICCC3) (Steliarova-Foucher et al, 2005). The LL subtype is effectively the same as the previously used grouping acute lymphoblastic leukaemia, as chronic LL is extremely rare among children.

The risk of cancer in adults from exposures experienced at work has been widely studied (Coggon et al, 2009). There has also been concern that occupational exposures at work may be risk factors for cancer in the children of workers (Colt and Blair, 1998). Results from previous epidemiological studies have shown no consistent association between parental occupational exposures and an increased risk of cancer in their offspring (Colt and Blair, 1998), though evidence for an association between paternal exposure to

*Correspondence: Dr TJ Keegan; E-mail: t.keegan@lancs.ac.uk Received 12 January 2012; revised 6 July 2012; accepted 12 July 2012; published online II September 2012 solvents and increased risk of leukaemia in their offspring is credible (Cordier, 2008). However, the interpretation of epidemiological evidence has been complicated by weak exposure assessments and limited case numbers.

The aetiology of childhood cancers, including leukaemia, is not well understood and there is continuing debate about the role of occupational and environmental exposures (Belson et al, 2007) as there is about the importance of the exposure route and timing (Roman et al, 2005). It is thought that exposures to the mother may be relevant during the intrauterine period and to the father preconceptually, when germ cells may be affected, and, for both parents, post-natally when residues from work may be brought into the home. In this study, we focus on paternal occupation because it is more completely recorded on birth registrations during our study period than maternal occupation (Fear et al, 1999a).

The main objective of this study is to investigate possible associations between paternal occupational exposure and childhood leukaemia in Great Britain using a matched case-control design. This study addresses some of the shortcomings of previous studies by drawing the study population from the National Registry of Childhood Tumours (NRCT), which holds a substantially complete record of all childhood cancers registered in the United Kingdom between 1962 and 2006 (Stiller et al, 1998). We use job title to derive an approximate measure of paternal social class and use this to investigate the possible independent associations between paternal social class and childhood leukaemia. 


\section{MATERIALS AND METHODS}

\section{Cases and controls}

The NRCT contained 17793 registered cases of leukaemia in children aged $<15$, born and diagnosed between 1962 and 2006 in Britain. A total of 691 cases were excluded because they were born overseas or adopted. Additionally, 338 for whom no birth registration could be found were excluded, leaving 16764 eligible cases for whom a birth record was available.

Control children $(n=16764)$ were selected from all birth registrations, held by the Office for National Statistics (ONS) or the General Register Office for Scotland (GROS). One control for each case was selected, matched on sex, date of birth ( \pm 6 months) and birth registration subdistrict.

The completeness of ascertainment of childhood cancer cases in the NRCT has varied over time, but it contains a substantially (>97\%) complete record of all registered cases of childhood cancer in the Britain from the early 1970s (Kroll et al, 2011a; Stiller, 2007).

Oxfordshire Research Ethics Committee (Oxfordshire REC C, Ref 07/Q1606/45) approved the use of these data in 2007.

\section{Coding of occupational groups}

In the UK, paternal occupation is routinely recorded on the public record of birth registrations where the father is named. Paternal occupation was abstracted verbatim from the case and control birth records as supplied by ONS and GROS.

Occupations were coded according to the 1980 Office of Population Censuses and Surveys (OPCS) Classification of Occupations (Office of Population Censuses and Surveys, 1980). Coding was carried out independently by two coders using the OPCS (now the ONS) coding manuals. Where the two coders disagreed, a third coded the occupation. Where the third coder agreed with one of the original coders that agreed code was assigned. Where all three coders disagreed the occupation was coded as 'uncodable'. At all stages, occupations were coded blind to the case-control status of the individuals. The 1980 classifications were converted to the codes used in the 1970 Classification of Occupations (Office of Population Censuses and Surveys, 1970) using a computer programme.

The 1970 codes were subsequently allocated to 1 or more of 33 occupational exposure groups, which have been described elsewhere (Fear et al, 1999a; Fear et al, 1999b). Briefly, the occupational exposure groups were derived by one of the authors (NTF) in conjunction with an occupational hygienist and an occupational researcher. Occupations not appearing in any of the 33 groups were classified 'unexposed' in all groups.

Occupations classified to one or more of the exposure groups were further defined as having either 'definite' (daily contact with the agent or contact at a high intensity) or 'possible' (exposure to the agent neither daily nor at high intensity) exposure in that group. Job titles could be coded to more than one occupational exposure group; for example, bus drivers appear as exposed in 'exhaust fumes', 'inhaled hydrocarbons' and 'social contact'. Each 1980 occupation code was then assigned to one of six social class codes from the 1980 OPCS Classification of Occupations. These social class codes were then categorised as either 'manual' (social classes IIIM, IV, V) or non-manual (social classes I, II, IIINM).

For 779 cases and 918 controls, paternal occupation was missing and these subjects were excluded from the analysis. For some (137 cases and 145 controls), it was not possible to assign an occupation code, or it was not possible to convert the 1980 code to a 1970 code (63 cases and coincidentally 63 controls (Figure 1). In these circumstances, the paternal occupation was coded as missing. For 1322 cases and 1577 controls, social class was classified as 'missing' because no occupation was given or the occupation falls outside the ONS social classifications (i.e., armed forces, student, independent means or sick). The 63 cases and 63 controls excluded from the occupation analysis were included in the social class analysis and appear in the results shown in Table 5.

In all, 1380 case/control fathers were classified as 'forces', comprising the armed forces, police force, fire service, and guards and related workers not elsewhere classified. Within the 'forces' group, social class code was unavailable for members of the armed forces, approximately half the group, and so the adjusted analysis was not performed for this exposure group.

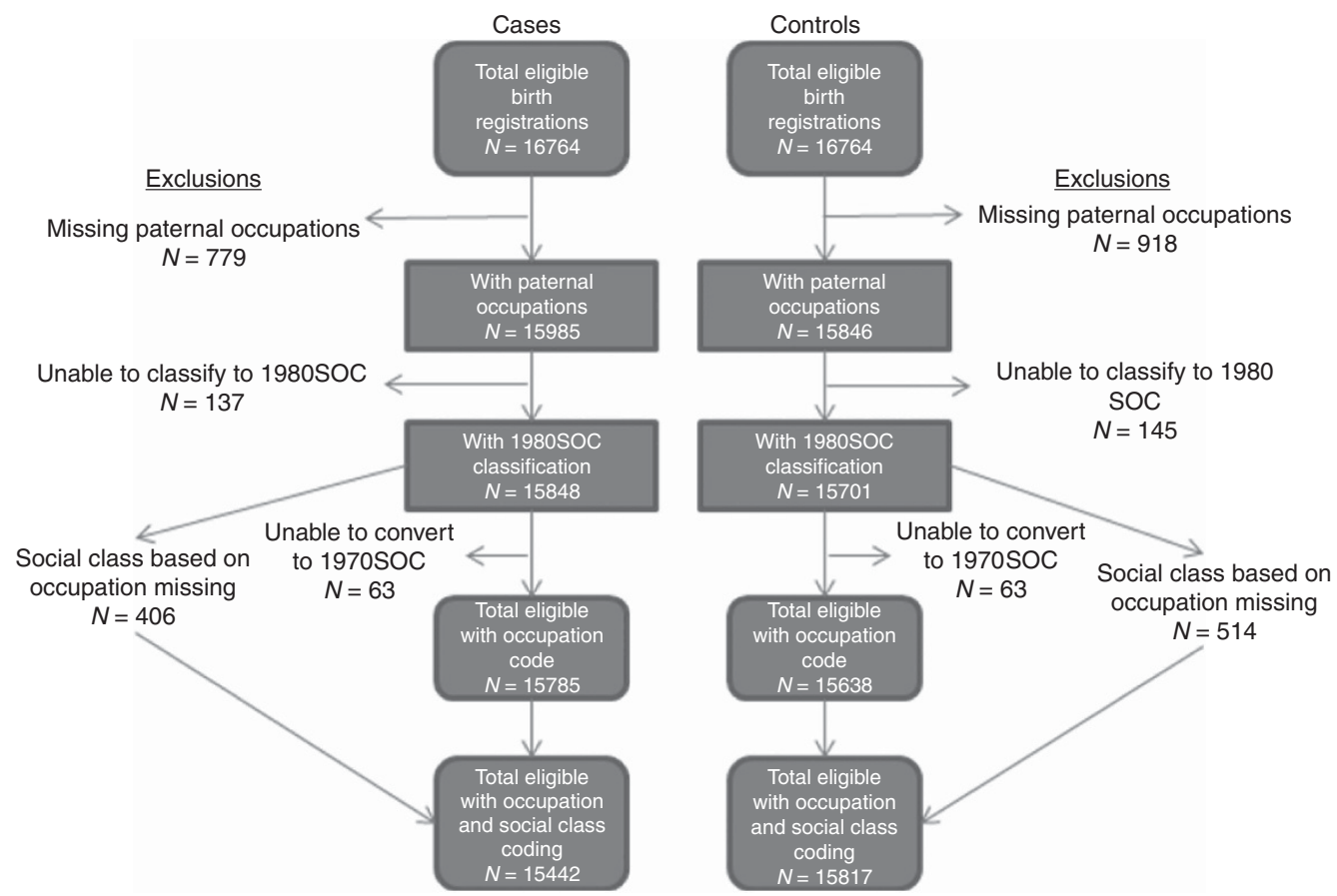

Figure I Flow chart showing the numbers of eligible cases and controls numbers included in the analysis. 


\section{Outcomes}

All cancers registered in the NRCT are coded to the ICCC, third edition (ICCC-3) (Steliarova-Foucher et al, 2005). Outcomes of interest in this study were total leukaemia (ICCC3 codes 11-15), LL (ICCC3 code 11), AML (ICCC3 code 12) and other leukaemia (ICCC3 codes 13-15).

\section{Analysis}

Odds ratios (ORs) and 95\% confidence intervals (95\% CIs) for our matched analysis were calculated using conditional logistic regression (Breslow and Day, 1980). Matching factors were: sex, period of birth and birth registration subdistrict. Odds ratios and 95\% CIs adjusted for social class (I, II, IIINM, IIIM, IV, V) were also generated. Our exposed population was those classified as 'definitely' exposed. The same analyses were repeated taking the exposed population as those with either 'definite' or 'possible' exposures (results not shown). Statistically significant results were defined as those where the $P$ value was $<0.05$.

To assess the impact of multiple statistical testing on the likelihood of any of the $33 P$ values for total leukaemia being significantly different from those expected by chance should the null hypothesis for each test be true, we plotted the empirical cumulative distribution of $P$ values whose null sampling distribution is assessed as uniform on $(0,1)$. To test for significant deviation from linearity, we compared the actual distribution with simulations of random samples from the distribution on $(0,1)$.

All analyses were carried out using STATA v. 11 (2005).

\section{Results}

After exclusions, a total 15785 (94\%) cases and 15638 (93\%) controls were included in the analyses of occupation and leukaemia risk, and 15442 (92\%) cases and 15187 (91\%) controls in the analyses of social class and leukaemia risk (Figure 1). Of the cases, 12288 (78\%) were LL, 2367 (15\%) were AML and 1130 (7\%) were classified as other leukaemia (Table 1). There was no significant difference between the birth regions of cases and controls. However, there was a difference in social class between the two groups, with a significantly higher percentage of nonmanual social class fathers of cases than of controls.

Table 2 shows estimates for the risk of total leukaemia by occupational exposure group. There are two exposure groups for which the risk of leukaemia is significantly less than 1.0: exposure to exhaust fumes and to lead. For one exposure group, social contact, leukaemia risk was significantly raised (OR 1.14, 1.05-1.23). These associations persisted following adjustment for social class.

For LL, a significantly raised OR was seen for paternal occupational social contact (OR 1.12, 1.02-1.22), but this became non-significant following adjustment for paternal occupational social class (Table 3 ). The OR for exposure to exhaust fumes at 0.9 was of borderline significance. No other significant associations emerged. For AML (Table 4), a significantly raised OR for paternal occupational social contact was observed (OR 1.25, 1.01-1.55) but this became non-significant after adjustment for paternal occupational social class (Table 4). Risk of AML was significantly reduced with paternal exposure to exhaust fumes and for the exposure group medical/healthcare. For other leukaemias, only exposure to electromagnetic fields (EMFs) (OR 1.64, 1.14-2.38) was associated with an increased risk. This relationship persisted after adjustment for social class (OR 1.60, 1.11-2.33) but was based on small numbers (119 informative pairs, data not shown).

When we plotted the empirical cumulative distribution of total leukaemia $P$ values and compared the actual distribution with simulations of random samples from the uniform distribution, we
Table I Leukaemia cases born and diagnosed in Great Britain between 1962 and 2006 for whom a birth record and ONS occupation code was available, and their matched controls

\begin{tabular}{|c|c|c|c|c|}
\hline & Cases & $\%$ & Controls & $\%$ \\
\hline \multicolumn{5}{|l|}{ Sex } \\
\hline Males & 8840 & 56 & 8740 & 56 \\
\hline Females & 6945 & 44 & 6898 & 44 \\
\hline Total & 15785 & 100 & 15638 & 100 \\
\hline \multicolumn{5}{|l|}{ Leukaemia subtype } \\
\hline Lymphoid leukaemia & 12288 & 78 & 12140 & 78 \\
\hline Acute myeloid leukaemia & 2367 & 15 & 2371 & 15 \\
\hline Other leukaemia & 1130 & 7 & 1127 & 7 \\
\hline Total leukaemia & 15785 & 100 & 15638 & 100 \\
\hline \multicolumn{5}{|l|}{ Birth year } \\
\hline $1962-1969$ & 3482 & 21 & 3457 & 22 \\
\hline 1970-1979 & 3759 & 24 & 3745 & 24 \\
\hline $1980-1989$ & 3971 & 25 & 3932 & 25 \\
\hline 1990-1999 & 3620 & 23 & 3564 & 23 \\
\hline 2000-2009 & 953 & 6 & 940 & 6 \\
\hline Total & 15785 & 100 & 15638 & 100 \\
\hline \multicolumn{5}{|l|}{ Social class } \\
\hline । & 1128 & 7 & 1032 & 7 \\
\hline$\|$ & 3300 & 21 & 3047 & 19 \\
\hline IIINM & 1901 & 12 & $172 \mid$ & 11 \\
\hline$\| M$ & 5470 & 35 & 5611 & 36 \\
\hline IV & 2628 & 17 & 2687 & 17 \\
\hline $\mathrm{V}$ & 952 & 6 & 1026 & 7 \\
\hline Not known & 406 & 3 & 514 & 3 \\
\hline Total & 15785 & 100 & 15638 & 100 \\
\hline \multicolumn{5}{|l|}{ Occupational status } \\
\hline Non-manual & 6329 & 40 & 5800 & 37 \\
\hline Manual & 9050 & 57 & 9324 & 60 \\
\hline Unknown & 406 & 3 & 514 & 3 \\
\hline Total & 15785 & 100 & 15638 & 100 \\
\hline \multicolumn{5}{|l|}{ Region } \\
\hline North & 897 & 6 & 895 & 6 \\
\hline Yorkshire and Humberside & 1403 & 9 & 1410 & 9 \\
\hline East Midlands & 1106 & 7 & 1043 & 7 \\
\hline East Anglia & 527 & 3 & 541 & 3 \\
\hline South East & 5094 & 32 & 5052 & 32 \\
\hline South West & 1247 & 8 & 1209 & 8 \\
\hline West Midlands & 1586 & 10 & 1600 & 10 \\
\hline North West & 1758 & 11 & 1698 & 11 \\
\hline Wales & 743 & 5 & 733 & 5 \\
\hline Scotland & 1416 & 9 & 1450 & 10 \\
\hline Not known & 8 & 0 & 7 & 0 \\
\hline Total & 15785 & 100 & 15638 & 100 \\
\hline
\end{tabular}

found that the likelihood of any $P$ value lying outside the range expected by chance was low.

When we examined risk of childhood leukaemia by paternal occupational social class, we found that higher paternal occupational social class was associated with increased leukaemia risk, thus children of professional/managerial fathers were at greater risk than those of manual labourers. This was almost entirely driven by the results for LL: OR $0.95(0.93-0.97)$ for each reduction in occupational social class (Table 5).

\section{DISCUSSION}

\section{Summary}

Our analysis, based on almost all cases of childhood leukaemia diagnosed in Great Britain between 1962 and 2006, showed a 
Table 2 Paternal occupational exposures and ORs with 95\% confidence intervals for total leukaemia

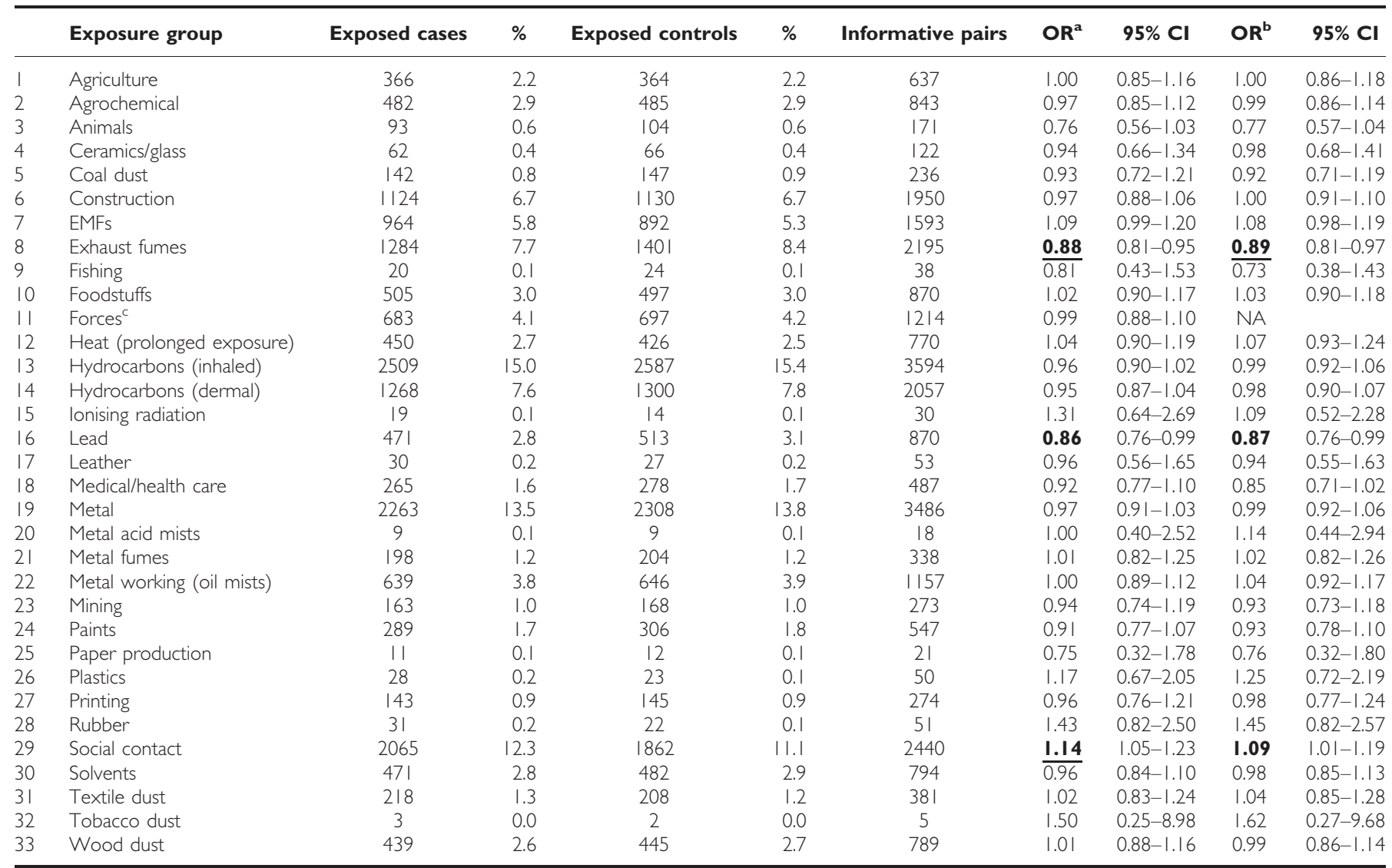

Abbreviations: EMF = electromagnetic field; ONS = Office for National Statistics; OR = odds ratio; $\mathrm{SES}=$ socioeconomic status. ORs are presented as unadjusted ${ }^{\mathrm{a}}$ and adjusted ${ }^{\mathrm{b}}$ for social class. ORs in bold indicate values that differ significantly from I $(P<0.05)$. ORs in bold and underlined indicate values that differ significantly from I $(P<0.0 \mathrm{I})$. ${ }^{\mathrm{a}} \mathrm{OR}$ with only the implicit adjustment for the matching factors: sex, registration subdistrict and period of registration. ${ }^{\mathrm{b}} \mathrm{OR}$ additionally adjusted for SES (based on ONS categories I, 2 , $3 N M, 3 M, 4,5$ defined by the father's declared occupation at the time of the child's birth). 'The group includes members of the fire service, police force and armed forces. Occupational social class was missing for members of the armed forces ( $n=300$ cases and 383 controls), leaving 626/I 222 informative pairs for the adjusted analysis. As a result the figure is omitted.

significantly increased risk of leukaemia overall, LL and AML with paternal occupational exposure to 'social contact'. After adjustment for paternal social class, the increased risk for total leukaemias with social contact persisted, whereas for LL and AML it became non-significant.

The risk for 'other leukaemias' was also raised significantly with paternal exposure to EMFs. This risk estimate was reduced slightly by adjustment for social class.

Our results also showed a statistically significant protective effect against total leukaemia and the subtypes LL and AML of exposure to exhaust fumes, and for total leukaemia with paternal exposure to lead, though the latter association was of borderline significance. The association with LL did not persist after adjustment for social class but those for AML with exhaust fumes and total leukaemia with lead did.

We also found that higher paternal social class was associated with a significantly raised risk of LL, and lower paternal social class with a (non-significant) decreased risk of LL. The trend of this association was significant.

\section{Comparison with previous studies}

There are a number of previous studies of risk of childhood leukaemia and paternal occupation. A number of these have, in contrast to our results, shown increased risk of leukaemias from paternal exposure to motor vehicle emissions (Colt and Blair, 1998). An analysis of the findings of 21 studies of childhood leukaemias and paternal occupation reported a pooled OR of 1.21 (1.11-1.32), though cautioned that variation in exposure assessment and outcome definitions did not make interpretation straightforward (McKinney et al, 2003). In this context, our result, suggesting a protective effect, is an anomaly and is likely to be the result of chance. The biological plausibility of the association between vehicle emissions and leukaemia is based on exposures to benzene; benzene is a component of exhaust fumes and IARC recommends that there is sufficient evidence for benzene to be a cause of leukaemias in adults, particularly for AML (International Agency for Research on Cancer, 1982). In our results, no other occupational exposure group in which benzene may have been a plausible component (hydrocarbons inhaled or solvents) was a risk factor for childhood leukaemia.

Our results are not in accord with the literature on paternal exposure to solvents and paints as risk factors for childhood leukaemia, for which there is reasonably reliable epidemiological evidence (Colt and Blair, 1998). For these exposures, for each outcome considered here, the ORs are unremarkable. Similarly, we saw no associations between paternal exposure to agriculture, agrochemicals or animals and childhood leukaemia, a finding in keeping with recent studies (Fear et al, 1998; Pearce et al, 2006). However, there is reasonably consistent epidemiological evidence, 
Table 3 Paternal occupational exposures and ORs with 95\% confidence intervals for lymphoid leukaemia

\begin{tabular}{|c|c|c|c|c|c|c|c|c|c|c|}
\hline & Exposure group & Exposed cases & $\%$ & Exposed controls & $\%$ & Informative pairs & $\mathbf{O R}^{\mathbf{a}}$ & $95 \% \mathrm{Cl}$ & $\mathbf{O R}^{\mathbf{b}}$ & $95 \% \mathrm{Cl}$ \\
\hline I & Agriculture & 280 & 2.1 & 275 & 2.1 & 479 & 1.00 & $0.84-1.20$ & $1.0 \mid$ & $0.84-1.22$ \\
\hline 2 & Agrochemical & 368 & 2.8 & 372 & 2.9 & 644 & 0.96 & $0.83-1.12$ & 0.98 & $0.84-1.15$ \\
\hline 3 & Animals & 73 & 0.6 & 82 & 0.6 & 136 & 0.74 & $0.53-1.04$ & 0.75 & $0.53-1.06$ \\
\hline 4 & Ceramics/glass & 46 & 0.4 & 49 & 0.4 & 89 & 0.93 & $0.62-1.42$ & 0.98 & $0.64-|.5|$ \\
\hline 5 & Coal dust & 102 & 0.8 & 109 & 0.8 & 176 & 0.91 & $0.68-1.23$ & 0.91 & $0.67-1.23$ \\
\hline 6 & Construction & 863 & 6.6 & 879 & 6.7 & 1513 & 0.95 & $0.86-1.05$ & 1.00 & $0.90-1.10$ \\
\hline 7 & EMFs & 742 & 5.7 & 685 & 5.3 & 1227 & 1.10 & $0.98-1.23$ & 1.10 & $0.98-1.23$ \\
\hline 8 & Exhaust fumes & 982 & 7.5 & 1046 & 8.0 & 1663 & 0.90 & $0.82-1.00$ & 0.93 & $0.84-1.02$ \\
\hline 9 & Fishing & 17 & 0.1 & 19 & 0.1 & 31 & 0.94 & $0.46-1.90$ & 0.84 & $0.41-1.76$ \\
\hline 10 & Foodstuffs & 391 & 3.0 & 392 & 3.0 & 682 & 1.00 & $0.86-1.16$ & $1.0 \mid$ & $0.87-1.18$ \\
\hline I | & Forces & 538 & 4.1 & 536 & 4.1 & 962 & 1.00 & $0.88-1.14$ & NA & \\
\hline 12 & Heat (prolonged exposure) & 348 & 2.7 & 338 & 2.6 & 600 & 0.99 & $0.85-1.17$ & 1.04 & $0.88-1.22$ \\
\hline 13 & Hydrocarbons (inhaled) & 1943 & 14.9 & 1984 & 15.2 & 2774 & 0.96 & $0.90-1.04$ & 1.00 & $0.93-1.09$ \\
\hline 14 & Hydrocarbons (dermal) & 994 & 7.6 & 1020 & 7.8 & 1616 & 0.94 & $0.85-1.04$ & 0.99 & $0.89-1.09$ \\
\hline 15 & lonising radiation & 16 & 0.1 & 12 & 0.1 & 26 & 1.17 & $0.54-2.52$ & 0.93 & $0.42-2.06$ \\
\hline 16 & Lead & 372 & 2.9 & 398 & 3.1 & 674 & 0.88 & $0.76-1.03$ & 0.90 & $0.77-1.05$ \\
\hline 17 & Leather & 26 & 0.2 & 17 & 0.1 & 39 & 1.29 & $0.69-2.44$ & 1.27 & $0.67-2.40$ \\
\hline 18 & Medical/health care & 217 & 1.7 & 206 & 1.6 & 378 & 1.04 & $0.85-1.28$ & 0.96 & $0.78-1.18$ \\
\hline 19 & Metal & 1769 & 13.6 & 1814 & 13.9 & 2736 & 0.97 & $0.90-1.04$ & 0.99 & $0.92-1.07$ \\
\hline 20 & Metal acid mists & 7 & 0.1 & 5 & 0.0 & 12 & 1.40 & $0.44-4.41$ & 1.76 & $0.51-6.01$ \\
\hline 21 & Metal fumes & 153 & 1.2 & 161 & 1.2 & 264 & 0.97 & $0.76-1.23$ & 0.99 & $0.77-1.26$ \\
\hline 22 & Metal working (oil mists) & 498 & 3.8 & 506 & 3.9 & 901 & 0.99 & $0.87-1.13$ & 1.04 & $0.91-1.19$ \\
\hline 23 & Mining & 118 & 0.9 & 128 & 1.0 & 209 & 0.88 & $0.67-1.16$ & 0.89 & $0.68-1.17$ \\
\hline 24 & Paints & 228 & 1.7 & 241 & 1.8 & 432 & 0.91 & $0.75-1.10$ & 0.94 & $0.77-1.14$ \\
\hline 25 & Paper production & 10 & 0.1 & 9 & 0.1 & 17 & 0.89 & $0.34-2.30$ & 0.91 & $0.35-2.36$ \\
\hline 26 & Plastics & 21 & 0.2 & 21 & 0.2 & 42 & 1.00 & $0.55-1.83$ & 1.08 & $0.59-1.97$ \\
\hline 27 & Printing & 115 & 0.9 & 115 & 0.9 & 221 & 0.99 & $0.76-1.29$ & 1.02 & $0.78-1.33$ \\
\hline 28 & Rubber & 24 & 0.2 & 14 & 0.1 & 36 & 1.77 & $0.90-3.49$ & 1.85 & $0.92-3.75$ \\
\hline 29 & Social contact & 1603 & 12.3 & 1448 & |l. I & 1912 & 1.12 & $1.02-1.22$ & 1.08 & $0.98-1.18$ \\
\hline 30 & Solvents & 374 & 2.9 & 380 & 2.9 & 636 & 0.97 & $0.83-1.13$ & 1.00 & $0.85-1.17$ \\
\hline 31 & Textile dust & 174 & 1.3 & 162 & 1.2 & 296 & 1.04 & $0.83-1.31$ & 1.07 & $0.85-1.35$ \\
\hline 32 & Tobacco dust & 3 & 0.0 & । & 0.0 & 4 & 3.00 & $0.31-28.84$ & 3.32 & $0.34-31.90$ \\
\hline 33 & Wood dust & 347 & 2.7 & 346 & 2.7 & 621 & 1.03 & $0.88-1.20$ & 1.03 & $0.87-1.21$ \\
\hline
\end{tabular}

Abbreviations: EMF = electromagnetic field; ONS = Office for National Statistics; OR = odds ratio. ORs are presented as unadjusted ${ }^{\mathrm{a}}$ and adjusted ${ }^{\mathrm{b}}$ for social class. ORs in bold indicate values that differ significantly from I $(P<0.05)$. ORs in bold and underlined indicate values that differ significantly from I $(P<0.0 \mathrm{I})$. ${ }^{\mathrm{a} O R}$ with only the implicit adjustment for the matching factors: sex, registration subdistrict and period of registration. ${ }^{\text {}}$ OR additionally adjusted for SES (based on ONS categories I, 2, 3NM, 3M, 4, 5 defined by the father's declared occupation at the time of the child's birth)

presented in a recently updated review, for paternal exposure to pesticides as a risk factor for childhood leukaemia, as well as a plausible role for the child's own exposure to pesticides in the aetiology of childhood cancer (Infante-Rivard and Weichenthal, 2007).

Occupational exposure to EMFs was a risk factor for other leukaemias, which persisted after adjustment for social class albeit based on small numbers. This adds to the body of evidence on paternal EMF exposure and childhood leukaemia, which to date is inconsistent (Feychting et al, 2000; Pearce et al, 2007).

In our study, social contact was a risk factor for childhood total leukaemia and both LL and AML separately. The risk estimates for total leukaemia were unaffected by adjustment for social class, whereas those for LL and AML remained raised but became nonsignificant on adjustment. This finding is in keeping with evidence that a father's high level of social contact is a risk factor for childhood leukaemia, with the suggestion that this pattern reflects an infective aetiology for childhood leukaemia (Kinlen et al, 2002; Pearce et al, 2004; Hug et al, 2010), though a recent case-control study of childhood cancer risks failed to support this (Fear et al, 2005).

Kinlen (1997) reported a significant positive trend in childhood leukaemia risk in rural areas of Britain (at ages 0-14, 0-4 and 5-14 years) in which high levels of population mixing was likely. These significant excess risks were seen across the occupational contact categories from the reference group through high to very high contact categories, particularly for paternal occupations connected with the construction industry and transport (Kinlen, 1997).
Kinlen and Bramald (2001) reported a case-control study in Scotland in which a positive association was found between rates of childhood leukaemia (0-4 years) in rural areas and paternal occupations that involved occupational contact. They observed no such relationship in urban areas, where it was taken that children are less isolated, and are consequently exposed to many infections from an early age (Kinlen and Bramald, 2001). This observation was supported by a similar study in Sweden (Kinlen et al, 2002).

When we examined leukaemia risk in children by the occupational social class of the father, we found that for LL and for total leukaemia there was an increased risk of childhood leukaemia in the higher social classes.

This is consistent with evidence from other registry-based studies of paternal socioeconomic status (SES) and childhood leukaemia (Borugian et al, 2005; Poole et al, 2006; Kroll et al, $2011 b$ ), but contrasts with evidence from an area-level analysis that showed raised ORs for leukaemia in children living in the lowincome municipalities (Raaschou-Nielsen et al, 2004). However, that paper also reported neutral ORs for the results of an analysis of risk of childhood leukaemia and paternal social class.

Additionally, our results are in accord with results from a casecontrol study of a matched area-level analysis of SES and leukaemia (cases $n=3835$ ) that showed a significantly reduced risk for childhood ALL in the most deprived SES category compared to the least (OR 0.76, 95\% CI 0.61-0.95), when cases whose parents had not been interviewed were excluded (Smith et al, 2006). 
Table 4 Paternal occupational exposures and ORs with 95\% confidence intervals for acute myeloid leukaemia

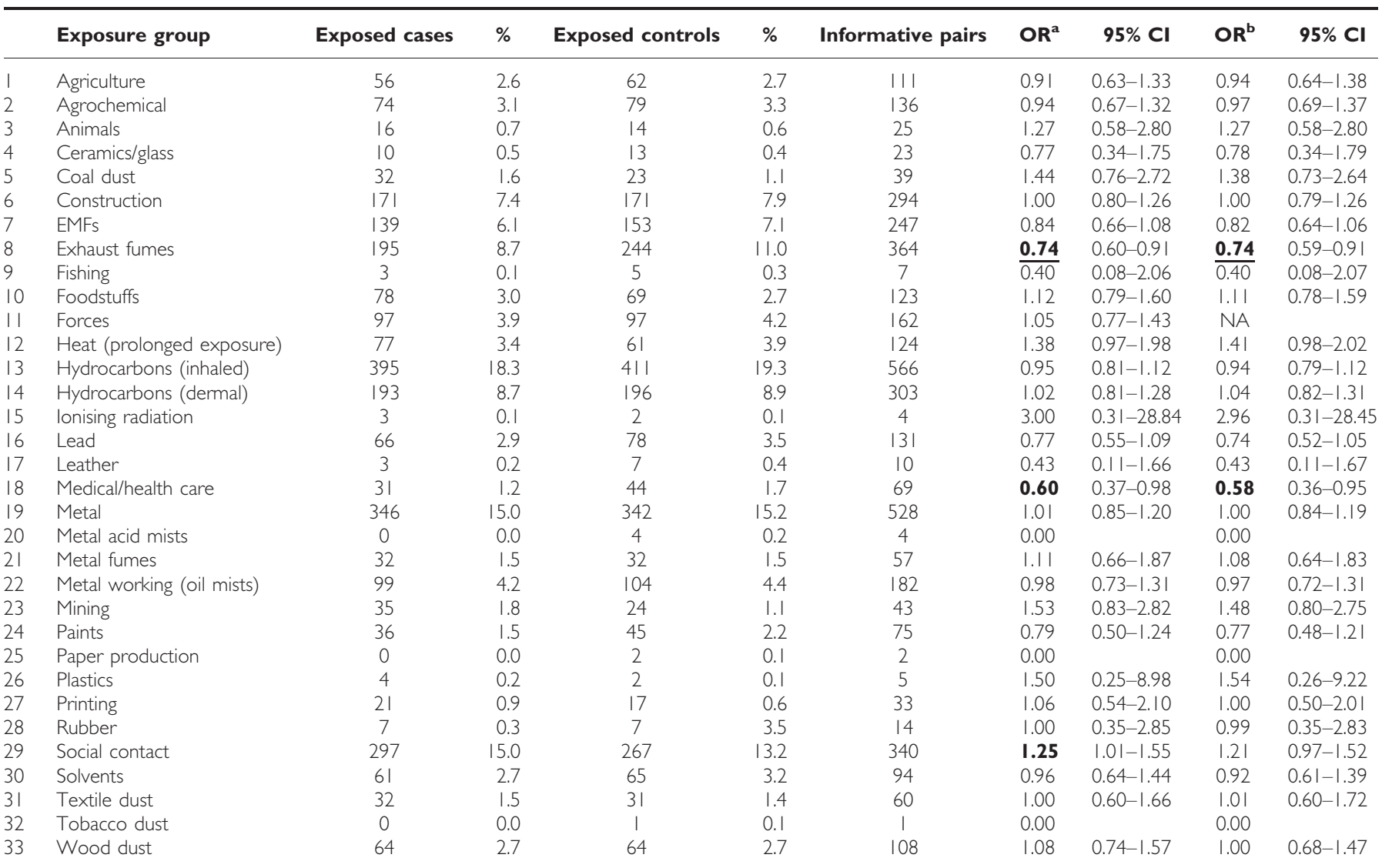

Abbreviations: $E M F=$ electromagnetic field; ONS = Office for National Statistics; OR = odds ratio; SES = socioeconomic status. ORs are presented as unadjusted ${ }^{\mathrm{a}}$ and adjusted ${ }^{\mathrm{b}}$ for social class. ORs in bold indicate values that differ significantly from I $(P<0.05)$. ORs in bold and underlined indicate values that differ significantly from I $(P<0.0 \mathrm{I})$. ${ }^{\mathrm{a}} \mathrm{OR}$ with only the implicit adjustment for the matching factors: sex, registration subdistrict and period of registration. ${ }^{\mathrm{b}} \mathrm{OR}$ additionally adjusted for SES (based on ONS categories I, 2, 3NM, 3M, 4, 5 defined by the father's declared occupation at the time of the child's birth).

Table 5 Leukaemia risk by paternal occupationally defined social class

\begin{tabular}{|c|c|c|c|c|c|c|c|c|c|}
\hline Social class of father & Controls & \multicolumn{2}{|c|}{ Lymphoid leukaemia } & \multicolumn{2}{|c|}{ Acute myeloid leukaemia } & \multicolumn{2}{|c|}{ Other leukaemia } & \multicolumn{2}{|c|}{ Total leukaemia } \\
\hline$\|$ & 3055 & 2624 & $1.16(1.05-1.28)$ & 458 & $1.12(0.88-1.41)$ & 223 & $1.17(0.85-1.60)$ & 3305 & $1.15(1.06-1.26)$ \\
\hline III Non-manual & 1721 & 1490 & $1.11(0.98-1.26)$ & 282 & $1.42(1.03-1.94)$ & 129 & $0.93(0.62-1.42)$ & 1901 & $1.13(1.01-1.27)$ \\
\hline III Manual & 5626 & 4268 & 1.00 & 822 & 1.00 & 397 & 1.00 & 5487 & 1.00 \\
\hline IV & 2687 & 2015 & $0.96(0.86-1.06)$ & 424 & $1.04(0.82-1.31)$ & 189 & $1.17(0.83-1.66)$ & 2628 & $0.98(0.89-1.08)$ \\
\hline
\end{tabular}

Abbreviations: $\mathrm{Cl}=$ confidence interval; ONS = Office for National Statistics; OR = odds ratio. The table includes 63 cases and 63 controls who had a social class code assigned but who had no 1970 occupation code assigned and were excluded from the occupation analysis. ORs in bold are significant at $P<0.05$; in bold and single underlined at $P<0.0$ I; in bold and double underlined at $P<0.00 \mathrm{I}$. ${ }^{a} \mathrm{OR}$ for the indicated ONS social class(es) with III Manual taken as the reference category. ${ }^{\mathrm{b}} \mathrm{OR}$ for each increase in occupational social class.

\section{Strengths and limitations}

The strengths of this study are that the analysis is based on case data drawn from the NRCT which has, over the period studied here, consistently high levels of case ascertainment (Kroll et al, 2011a). A problem with case-control studies that interview participants is recall and participation bias. The level of such bias here is likely to be minimal, as the study used routinely collected data and occupation was documented before diagnosis. The exposure assessment used a well-established occupational and exposure classification, (Fear et al, 1999a) to which father's occupation was coded blind to case-control status. However, our method used occupation recorded at the time of birth, and this might differ from an occupation held at a more aetiologically important time period. Additionally, we have no information on the frequency or duration of exposure and occupational practices, and exposures may have changed during the long study period that would lead to exposure misclassification. 
It is also possible that during our long study period some cases of childhood leukaemia were not diagnosed or registered. If those cases were more likely to be from the lower social classes, there could be fewer cases of leukaemia in the lower social class groups relative to the higher class groups, and this might possibly explain the social class effect we detected.

In this study, we have analysed risk of leukaemia by paternal occupational exposure for each major leukaemia subgroup. This is important as each may have a different aetiology (Ross et al, 1994; McKinney et al, 2003). Of those risks that were raised, social contact was associated with total leukaemia, LL and AML, and EMF exposure was associated with other leukaemias. For total leukaemias, this association remained after adjustment for paternal occupational social class but for the subtypes LL and AML it did not.

\section{Interpretation}

One possible reason why our data have not shown associations between paternal occupational exposures such as solvents and exhaust fumes is exposure misclassification. The exposure windows when a paternal occupational exposure may plausibly lead to childhood leukaemia are at periconception, as a result of effects of the exposure on germ cells, and during pregnancy and after birth, when contaminants brought home from the workplace by the father may affect the embryo or young child (McKinney et al, 1991; Olshan et al, 2000). As we have no information about paternal occupation before or after a child's birth was registered, the occupation (and hence exposure) may have been different and exposure misclassification may have arisen as a result; however, this applies equally to cases and controls. Additionally, we have no direct information about the intensity or frequency of exposure within groups, and, over the 45 years for which we have data,

\section{REFERENCES}

Belson M, Kingsley B, Holmes A (2007) Risk factors for acute leukemia in children: a review. Environ Health Perspect 115(1): 138-145

Borugian MJ, Spinelli JJ, Mezei G, Wilkins R, Abanto Z, McBride ML (2005) Childhood leukemia and socioeconomic status in Canada. Epidemiology 16(4): 526-531

Breslow NE, Day NE (1980) Statistical Methods in Cancer Research Volume 1 - The Analysis of Case-Control Studies. IARC Scientific Publications No. 32. International Agency for Research on Cancer: Lyon

Coggon D, Harris EC, Brown T, Rice S, Palmer K (2009) Occupational mortality in England and Wales, 1991-2000. Office for National Statistics: Cardiff

Colt JS, Blair A (1998) Parental occupational exposures and risk of childhood cancer. Environ Health Perspect 106(Suppl 3): 909-925

Cordier S (2008) Evidence for a role of paternal exposures in developmental toxicity. Basic Clin Pharmacol Toxicol 102(2): 176-181

Fear N, Roman E, Reeves G, Pannett B (1999a) Father's occupation and childhood mortality: analysis of routinely collected data. Health Stat Q 2: 7-15; http://www.statistics.gov.uk/downloads/theme_health/HSQ2Book.pdf

Fear NT, Roman E, Reeves G, Pannett B (1998) Childhood cancer and paternal employment in agriculture: the role of pesticides. $\mathrm{Br} \mathrm{J}$ Cancer 77(5): 825-829

Fear NT, Roman E, Reeves G, Pannett B (1999b) Are the children of fathers whose jobs involve contact with many people at an increased risk of leukaemia? Occup Environ Med 56(7): 438-442

Fear NT, Simpson J, Roman E, on behalf of the United Kingdom Childhood Cancer Study Investigators (2005) Childhood cancer and social contact: the role of paternal occupation (United kingdom). Cancer Causes Control 16(9): 1091-1097

Feychting M, Floderus B, Ahlbom A (2000) Parental occupational exposure to magnetic fields and childhood cancer (Sweden). Cancer Causes Control 11(2): 151-156

Hug K, Grize L, Seidler A, Kaatsch P, Schuz J (2010) Parental occupational exposure to extremely low frequency magnetic fields and childhood cancer: a German case-control study. Am J Epidemiol 171(1): 27-35 actual exposures may have changed within exposure groups as a result of changing workplace practices. The need for specific information about exposures and their timing to which we draw attention has been highlighted previously (Schuz et al, 2003).

In our analysis, we carried out multiple comparisons that may have resulted in a number of associations having arisen by chance. Our analysis showed that the significant $P$ values for the lowered ORs are unlikely to be real. Although this fits with expectations of the nature of the relationship between paternal exposure to lead and exhaust fumes and childhood leukaemia, it is also the case that the significantly raised ORs we have reported may also have arisen by chance. Although the literature would suggest that the latter association is more plausible, our results should still be interpreted with caution. Other, unmeasured, risk factors may also explain the association between social class and childhood leukaemia.

In conclusion, although this study adds only limited evidence that individual paternal occupational exposures are risk factors for childhood leukaemia it does provide additional evidence for higher occupational social class being a risk factor for childhood leukaemia. Other risk factors associated with social class may therefore have a more important part than specific occupational exposures.

\section{ACKNOWLEDGEMENTS}

We thank Professor Peter Diggle of the Lancaster University for his statistical advice on assessment of the impact of multiple testing. The work of the Childhood Cancer Research Group (CCRG) is supported by the CHILDREN with CANCER (UK) charity, the Scottish Government and the Department of Health for England and Wales.

Infante-Rivard C, Weichenthal S (2007) Pesticides and childhood cancer: an update of Zahm and Ward's 1998 review. J Toxicol Environ Health Part B 10(1-2): 81-99

International Agency for Research on Cancer (1982) IARC Monographs on the Evaluation of the Carcinogenic Risk of Chemicals to Humans: Some Industrial Chemicals and Dyestuffs, vol. 29. IARC: Lyon, France

Kinlen L, Jiang J, Hemminki K (2002) A case-control study of childhood leukaemia and paternal occupational contact level in Sweden. Br J Cancer 86(5): $732-737$

Kinlen LJ (1997) High-contact paternal occupations, infection and childhood leukaemia: five studies of unusual population-mixing of adults. $\mathrm{Br} \mathrm{J}$ Cancer 76(12): 1539-1545

Kinlen LJ, Bramald S (2001) Paternal occupational contact level and childhood leukaemia in rural Scotland: a case-control study. $\mathrm{Br} \mathrm{J}$ Cancer 84(7): 1002-1007

Kroll ME, Murphy MFG, Carpenter LM, Stiller CA (2011a) Childhood cancer registration in Britain: capture-recapture estimates of completeness of ascertainment. Br J Cancer 104(7): 1227-1233

Kroll ME, Stiller CA, Murphy MFG, Carpenter LM (2011b) Childhood leukaemia and socioeconomic stauts in England and Wales 1976-2005 evidence of higher incidence in relatively affluent communities persists over time. Br J Cancer 105(11): 1783-1787

McKinney PA, Alexander FE, Cartwright RA, Parker L (1991) Parental occupations of children with leukaemia in West Cumbria, North Humberside, and Gateshead. BMJ 302(6778): 681-687

McKinney PA, Fear NT, Stockton D, on behalf of the UK Childhood Cancer Study Investigators (2003) Parental occupation at periconception: findings from the United Kingdom Childhood Cancer Study. Occup Environ Med 60(12): 901-909

Office of Population Censuses and Surveys (1970) Classification of Occupations. HMSO: London

Office of Population Censuses and Surveys (1980) Classification of Occupations. HMSO: London 
Olshan AF, Anderson L, Roman E, Fear N, Wolff M, Whyatt R, Vu V, Diwan BA, Potischman N (2000) Workshop to identify critical windows of exposure for children's health: cancer work group summary. Environ Health Perspect 108(Supplement 3): 595-597

Parkin DM, Kramrov E, Draper GJ, Masuyer E, Michaelis J, Neglia J, Qureshi S, Stiller CA (1998) International Incidence of Childhood Cancer Vol. 2, IARC Scientific Publications No. 144. International Agency for Research on Cancer: Lyon

Pearce MS, Cotterill SJ, Parker L (2004) Fathers' occupational contacts and risk of childhood leukemia and non-hodgkin lymphoma. Epidemiology 15(3): 352-356

Pearce MS, Hammal DM, Dorak MT, McNally RJ, Parker L (2006) Paternal occupational exposure to pesticides or herbicides as risk factors for cancer in children and young adults: a case-control study from the North of England. Arch Environ Occup Health 61(3): 138-144

Pearce MS, Hammal DM, Dorak MT, McNally RJQ, Parker L (2007) Paternal occupational exposure to electro-magnetic fields as a risk factor for cancer in children and young adults: a case-control study from the North of England. Pediatr Blood Cancer 49(3): 280-286

Poole C, Greenland S, Luetters C, Kelsey JL, Mezei G (2006) Socioeconomic status and childhood leukaemia: a review. Int $J$ Epidemiol 35(2): 370-384

Raaschou-Nielsen O, Obel J, Dalton S, Tjonneland A, Hansen J (2004) Socioeconomic status and risk of childhood leukaemia in Denmark. Scand J Public Health 32(4): 279-286

Roman E, Simpson J, Ansell P, Lightfoot T, Mitchell C, Eden TOB, on behalf of the United Kingdom Childhood Cancer Study Investigators (2005)
Perinatal and reproductive factors: a report on haematological malignancies from the UKCCS. Eur J Cancer 41(5): 749-759

Ross JA, Davies SM, Potter JD, Robison LL (1994) Epidemiology of childhood leukemia, with a focus on infants. Epidemiol Rev 16(2): 243-272

Schuz J, Spector LG, Ross JA (2003) Bias in studies of parental self-reported occupational exposure and childhood cancer. Am J Epidemiol 158(7): 710-716

Smith A, Roman E, Simpson J, Ansell P, Fear NT, Eden T (2006) Childhood leukaemia and socioeconomic status: fact or artefact? A report from the United Kingdom childhood cancer study (UKCCS). Int J Epidemiol 35(6): $1504-1513$

StataCorp LP (2005) Stata Statistical Software: Release 9. StataCorp LP: College Station, TX

Steliarova-Foucher E, Stiller C, Lacour B, Kaatsch P (2005) International classification of childhood cancer, third edition. Cancer 103(7): 1457-1467

Stiller C (2007) Childhood Cancer in Britain: Incidence, Survival, Mortality. Oxford University Press: Oxford

Stiller CA, Allen MB, Brownbill PA, Draper GJ, Eatock EM, Loach MJ, Vincent TJ (1998) United Kingdom: national registry of childhood tumours, England and Wales, 1981-1990. In International Incidence of Childhood Cancer, Parkin DM, Kram rov E, Draper GJ, Masuyer E, Michaelis J, Qureshi S, Stiller CA (eds). Vol. 2, pp 365-367. IARC Scientific Publications No. 144: Lyon

Swerdlow A, dos-Santos-Silva I, Doll R (2001) Cancer Incidence and Mortality in England and Wales: Trends and Risk Factors. Oxford University Press: New York

This work is published under the standard license to publish agreement. After 12 months the work will become freely available and the license terms will switch to a Creative Commons Attribution-NonCommercial-Share Alike 3.0 Unported License. 